\title{
Análise sensorial dos grãos de soja (Glycine max (L.) Merril) tostados por diferentes tratamentos
}

\author{
Sensorial analysis of soybean grains (Glycine max (L.) Merril) roasted by different treatments
}

\author{
Mônica Alves FELIX ${ }^{1}$, Solange Guidolin CANNIATTI BRAZACA ${ }^{2 \star}$, \\ Flávia Maria Vasques Farinazzi MACHADO ${ }^{3}$
}

\section{Resumo}

A soja tem importância para a saúde e seu consumo tem aumentado devido principalmente aos diversos produtos presentes no mercado. Prevenindo a ação das enzimas lipoxigenases há melhora na aceitação dos produtos derivados da soja. Vários processos tecnológicos podem evitar a ação da enzima lipoxigenase, a qual pode causar atributos sensoriais que causam rejeição no consumo de grãos de soja. A pesquisa teve por objetivo verificar a aceitabilidade dos grãos de soja tostados por diferentes tratamentos. Em grãos de soja previamente macerados, com as cascas retiradas, foram realizados cinco tratamentos: T1 e T2 - com secagem prévia + 10 e 15 minutos de forno, respectivamente; $\mathrm{T} 3$, T4 e T5 - sem secagem prévia $+45,50$ e 60 minutos de forno. O T6, controle, recebeu o mesmo tratamento, foi seco em estufa $\left(55^{\circ} \mathrm{C}\right)$ durante 31 horas. O comportamento dos provadores em relação ao consumo da soja não condiz com o conhecimento da importância para a saúde e a facilidade de aquisição do hábito de consumo, não havendo diferença para idade ou sexo. O tratamento que promoveu a maior aceitabilidade dos grãos de soja tostados foi o que recebeu o tempo intermediário de 50 minutos, sem secagem prévia.

Palavras-chave: soja; tostagem; aceitabilidade; consumo.

\begin{abstract}
Soybeans have been gaining prominence due to their potential benefits to health, Nonetheless, the presence of lipoxygenase in the grains can lead to low acceptance. Several processes have been used to improve the acceptance of grain. Different processes result in products with various sensory characteristics. The aim of this research was to check the acceptability of roasted soybeans using different treatments. Soybeans previously macerated and removed from the shell were subjected to five treatments: T1 and T2 - with pre-drying +10 and 15 minutes in the oven, respectively; T3, T4, and T5 - without pre-drying $+45,50$, and 60 minutes in the oven. The control was dried in an oven $\left(55^{\circ} \mathrm{C}\right)$ for 31 hours. The panelists' response in relation to consumption of soybean does not agree with its importance to health and with the easy changing of the consumption habits with no differences regarding age or sex. The treatment that promoted the greatest acceptability of roasted soybeans was the 50 - minute group without pre-drying.

Keywords: soybean; roasting; acceptance; consumption.
\end{abstract}

\section{Introdução}

A divulgação na mídia dos benefícios da soja à saúde está ocasionando mudanças no conceito dos consumidores em relação ao grão. A soja representa uma das commodities com maiores promessas de revolucionar o mercado dos alimentos funcionais no Brasil e no mundo (EMPRESA..., 2003). Vários estudos têm demonstrado que o consumo de grãos ou subprodutos da soja está frequentemente associado com a redução do risco de inúmeras doenças, tais como câncer de esôfago, pulmão, próstata, mama e cólon/reto, doenças cardiovasculares, osteoporose, diabetes e sintomas da menopausa (CHUNG et al., 1996; CLARK et al., 1996; GALLAGHER et al., 2000; MONTEIRO et al., 2004).

Dentre a cultura de grãos, a soja se caracteriza como a mais importante do País. O complexo soja, que compreende grãos, farelo e óleo, tem captado divisas no mercado internacional. A safra de 2005/2006 para soja foi de 53.413.900 mil toneladas (COMPANHIA..., 2007).

A demanda mundial por soja e subprodutos está em franco crescimento. Entre os fatores estão, não somente o aumento do consumo na alimentação humana, mas também o aumento da produção animal no mundo (CHIARELLO, 2002).

Para Dalla-Corte, Moda-Cirino e Scholz (2003), as qualidades tecnológicas, sensoriais e nutricionais das leguminosas são determinadas em parte pelo genótipo e influenciadas pelas condições do ambiente durante o desenvolvimento da planta e dos grãos. De acordo com esses autores, a qualidade dos grãos para cozimento é afetada pelo clima, cultivo, pós-colheita, armazenamento e tecnologia do processamento.

Recebido para publicação em 31/7/2008

Aceito para publicação em 31/10/2009 (003735)

1 Ciência e Tecnologia de Alimentos, Escola Superior de Agricultura "Luiz de Queiroz" - ESALQ, Universidade de São Paulo - USP

2 Departamento de Agroindústria, Alimentos e Nutrição, Escola Superior de Agricultura "Luiz de Queiroz" - ESALQ, Universidade de São Paulo - USP,

Av. Pádua Dias, 11, CP 9, CEP 13418-900, Piracicaba - SP, Brasil, E-mail: sgcbraza@esalq.usp.br

3 Departamento de Tecnologia em Alimentos, Faculdade de Tecnologia - FATEC, Marília - SP, Brasil, E-mail: farinazzimachado@hotmail.com

${ }^{*}$ A quem a correspondência deve ser enviada 
Os produtos de soja estão sendo usados em maior quantidade, por exemplo, as bebidas à base de soja que tiveram expansão de penetração nos domicílios da ordem de 147\% entre os anos de 2001 e 2004 (OLIVEIRA; CARVALHO, 2006). As restrições por parte dos consumidores ocidentais, devido ao sabor característico denominado beany flavor (RACKIS; SESSA; HONIG, 1979) pode ser controlada com o processamento adequado dos grãos na manufatura dos produtos. O beany flavoré originado da associação de compostos carbonílicos de cadeia curta com a fração proteica. Estes compostos são produtos finais de uma série de reações que se inicia com a hidroperoxidação de ácidos graxos polinsaturados, catalisados por lipoxigenases (AXELROD; CHEESBROUGH; LAAKSO, 1981; TORRES-PENARANDA et al., 1998; TORRES-PENARANDA; REITMEIER, 2001).

O processo de branqueamento pode inativar as lipoxigenases em soja (SETH; NATH, 1988) eliminando o problema de off flavour relacionado à ação da enzima (SAVAGE et al., 1995). O branqueamento por 90 segundos antes do processo de aquecimento foi efetivo para inativar $99 \%$ da atividade das lipoxigenases (MOZZONI, MORAWICKI, CHEN, 2009). Sheu e Chen (1991) recomendam o branqueamento até não ter mais ação das lipoxigenases. A utilização de alta pressão ou a combinação de temperatura e pressão é efetiva na inativação das lipoxigenases em grãos e extrato de soja. Utilizando somente pressão, são necessários $800 \mathrm{MPa}$ e na combinação de temperatura e pressão há necessidade de atingir temperatura de $60^{\circ} \mathrm{C}$ e $600 \mathrm{MPa}$ (VEN; MATSER; BERG, 2005).

Alguns produtos podem não apresentar beany flavor, como o constatado por King et al. (2001) para bebidas de soja preparadas com grãos com e sem lipoxigenase, porém Silva et al. (2007), avaliando bebidas preparadas com soja com e sem lipoxigenase, tratadas pelo mesmo processo, constataram que o extrato de grãos de soja sem lipoxigenase com $10 \%$ de diluição resultou na bebida de melhor aceitação, consistência próxima ao ideal e com maior porcentagem de intenção de compra.

$\mathrm{O}$ tratamento térmico tem sido usado para melhorar o valor nutricional e sensorial da soja, porém este tratamento deve ser controlado para evitar a destruição de aminoácidos importantes e a diminuição da biodisponibilidade de outros nutrientes (VASCONCELOS et al., 2001).

Mesmo o Brasil sendo o segundo maior produtor de soja do mundo (EMPRESA..., 2003), há carência de estudos que caracterizem aparência, aroma, textura e sabor dos grãos das diversas variedades de soja, ou seja, não se conhece o perfil sensorial desse grão. Porém, tem-se reconhecido a importância das características físicas e sensoriais na aceitação pelos consumidores (CANTO; TURATTI, 1989). A determinação da aceitação pelo consumidor é parte crucial no processo de desenvolvimento ou melhoramento de produtos (MOSKOWISTZ, 1988). Pelo método de aceitação, pode ser estudado o quanto os consumidores gostam ou não de um determinado alimento (MEILGAARD; CIVILLE; CARR, 1991; CLEMENTI et al., 1990; STONE; SIDEL, 2004). Segundo Behrens e Silva (2004), as indústrias de alimentos devem investir nos aspectos sensoriais e nos fatores benéficos à saúde para alcançar sucesso no mercado de produtos de soja.
Considerando o aumento no consumo da soja em grãos tostados na alimentação humana, este trabalho teve como objetivo verificar a aceitabilidade dos grãos de soja tostados por diferentes tratamentos.

\section{Material e métodos}

\subsection{Matéria-prima}

A matéria-prima utilizada para a realização do experimento foram grãos de soja (Glycine max (L.) Merrill) doados pelo Departamento de Genética da Escola Superior de Agricultura "Luiz de Queiroz" - ESALQ/USP, cultivar BRS 133, safra 2002/2003, cultivada na Estação Experimental de Anhembi ESALQ/USP. Os grãos de soja crus foram lavados, macerados em água deionizada na proporção 1:3 (14 horas). A água foi descartada e a casca dos grãos foi retirada manualmente. Foi realizado teste preliminar em que foram definidos os tratamentos a serem empregados com e sem secagem prévia. Após a retirada da casca, os grãos foram submetidos aos seguintes tratamentos:

- Tratamento 1- ST10: secagem em estufa por 8 horas $\left(55^{\circ} \mathrm{C}\right.$ ), tostagem em forno convencional (a gás) por 10 minutos à temperatura de $220^{\circ} \mathrm{C}$;

- Tratamento 2- ST15: secagem em estufa por 8 horas $\left(55^{\circ} \mathrm{C}\right)$, tostagem em forno convencional (a gás) por 15 minutos à temperatura de $220^{\circ} \mathrm{C}$;

- Tratamento 3- T45: tostagem em forno convencional (a gás) por 45 minutos à temperatura de $220^{\circ} \mathrm{C}$;

- Tratamento 4- T50: tostagem em forno convencional (a gás) por 50 minutos à temperatura de $220^{\circ} \mathrm{C}$;

- Tratamento 5- T60: tostagem em forno convencional (a gás) por 60 minutos à temperatura de $220^{\circ} \mathrm{C}$; e

- Tratamento 6- C: Controle - secagem em estufa por 31 horas a $55^{\circ} \mathrm{C}$.

\subsection{Análise sensorial}

A análise sensorial foi realizada no Laboratório de Análise Sensorial do Departamento de Agroindústria, Alimentos e Nutrição da ESALQ/USP. Foram consideradas as habilidades na percepção das diferentes amostras de grãos de soja tostados em relação ao aroma, sabor, textura e aparência, através da escala hedônica de nove pontos (aceitabilidade) segundo Chaves e Sproesser (1996). O modelo utilizado pode ser verificado na Figura 1.

Foram selecionados aleatoriamente 40 provadores não treinados, entre frequentadores do Campus da Escola Superior de Agricultura "Luiz de Queiroz", sendo adultos saudáveis, de 18 a 50 anos, de ambos os sexos, sem vínculo de subordinação com os pesquisadores e que manifestaram seu consentimento assinando o termo de consentimento livre e esclarecido conforme a Resolução 196/96 do Ministério da Saúde (BRASIL, 2003). O projeto (processo 214/2004) foi previamente aprovado pelo Comitê de Ética em Pesquisa da Faculdade de Odontologia da Universidade de Campinas que se localiza na cidade de 
1. Qual a sua idade? 18-21 anos ( ) 22-25 anos ( ) 26-29 anos mais de 30 ( )

2. Qual o seu sexo? Feminino ( ) Masculino ( )

3. Com que frequência você consome grãos de soja ou derivados?

diariamente( ) semanalmente( ) quinzenalmente ( ) mensalmente( ) raramente( ) nunca( )

4. Você acredita que o consumo de grãos de soja ou derivados melhora a saúde? Sim ( ) Não ( )

5. Você acha fácil adquirir o hábito de consumo de grãos de soja ou derivados? Sim ( ) Não ( )

6. Avalie cada amostra quanto à aparência e indique o quanto você gostou ou desgostou utilizando a escala abaixo:
1- Desgostei muitíssimo
6- Gostei ligeiramente
2- Desgostei muito
7- Gostei regularmente
3- Desgostei regularmente
8- Gostei muito
4- Desgostei ligeiramente
9- Gostei muitíssimo

5- Indiferente

\begin{tabular}{|c|c|}
\hline Código da amostra & Valor da nota \\
\hline & \\
\hline & \\
\hline & \\
\hline & \\
\hline & \\
\hline
\end{tabular}

7. Avalie cada amostra quanto ao aroma e indique o quanto você gostou ou desgostou utilizando a escala abaixo:

1- Desgostei muitíssimo

2- Desgostei muito

3- Desgostei regularmente

4- Desgostei ligeiramente

5- Indiferente
6- Gostei ligeiramente

7- Gostei regularmente

8- Gostei muito

9- Gostei muitíssimo

\begin{tabular}{|l|l|}
\hline Código da amostra & Valor da nota \\
\hline & \\
\hline & \\
\hline & \\
\hline & \\
\hline & \\
\hline
\end{tabular}

8. Avalie cada amostra quanto ao sabor e indique o quanto você gostou ou desgostou utilizando a escala abaixo:

1- Desgostei muitíssimo

2- Desgostei muito

3- Desgostei regularmente

4- Desgostei ligeiramente

5- Indiferente

\begin{tabular}{|c|c|}
\hline Código da amostra & Valor da nota \\
\hline & \\
\hline & \\
\hline & \\
\hline & \\
\hline & \\
\hline
\end{tabular}

9. Avalie cada amostra quanto à textura e indique o quanto você gostou ou desgostou utilizando a escala abaixo:
1- Desgostei muitíssimo
6- Gostei ligeiramente
2- Desgostei muito
7- Gostei regularmente
3- Desgostei regularmente
8- Gostei muito
4- Desgostei ligeiramente
9- Gostei muitíssimo

5- Indiferente

\begin{tabular}{|l|l|}
\hline Código da amostra & Valor da nota \\
\hline & \\
\hline & \\
\hline & \\
\hline & \\
\hline & \\
\hline
\end{tabular}

Figura 1. Ficha de avaliação sensorial dos grãos de soja tratados por diferentes tratamentos. 
Piracicaba, SP. Os testes foram realizados no período das 9 às 11 horas da manhã e das 14 às 16 horas, do mesmo dia. Os provadores realizaram os testes em cabines individuais, com luz branca, em temperatura ambiente e com copo de água descartável com água potável para limpeza da boca entre as avaliações das amostras. Cada provador recebeu seis amostras de grãos de soja tostados, em porções de $10 \mathrm{~g}$ por amostra, sendo uma amostra para cada tratamento, adicionada de $2 \%$ de sal, que foi servida em pratos brancos codificados com números de três dígitos escolhidos de forma aleatória.

Para a obtenção dos dados, foram utilizadas 9 questões que são apresentadas na Figura 1.

\subsection{Análise estatística}

O delineamento estatístico foi inteiramente casualizado, com três repetições para todas as análises. Realizou-se análise de variância pelo teste $F$ e comparação das médias obtidas nos diferentes tratamentos segundo teste de Tukey $(\mathrm{p}<0,05)$ (PIMENTEL-GOMES, 1982) através do programa Statistical Analysis System (STATISTICAL..., 1996). Foi realizado também o teste de independência. Assim, foram feitas tabelas de contingência para cada cruzamento das variáveis estudadas, utilizando-se a estatística do $\chi^{2}$ (Qui-quadrado) de Pearson para inferência (BURT, 1950; ANDERSEN, 1991; GREENACRE, 1993).

\section{Resultados e discussão}

A análise sensorial foi realizada em uma população com faixa etária predominante de 18 a 21 anos (35\%), seguida pela de 22 a 25 anos (28\%). Os que se encontravam com mais de 30 anos representaram $20 \%$ do total, e os que estavam na faixa etária de 26 a 29 anos, 17\%. Portanto, nota-se que mais de $60 \%$ dos provadores se encontravam entre 18 e 25 anos, isso é justificado pelo fato de que a maioria dos voluntários era composta por estudantes universitários. Quanto ao sexo, $58 \%$ dos provadores são do sexo feminino e $42 \%$ do masculino.

É possível verificar, através da Figura 2, que a maioria dos provadores raramente consome grãos de soja ou derivados (45\%), 25\% consomem os grãos ou derivados semanalmente, $13 \%$ o fazem mensalmente e $5 \%$ nunca consomem. Já os que consomem os grãos ou derivados quinzenalmente e diariamente representou uma menor parte da população em questão, com 8 e $5 \%$, respectivamente. Com isso, verificou-se que a soja em grão e seus derivados são apreciados por um segmento pequeno da população.

Os provadores consideram que a soja tenha potencial para a melhora da saúde (95\% dos provadores). Esse resultado sugere que essa população conhece o valor da soja como alimento, pois nos últimos anos a mídia brasileira tem divulgado intensivamente as pesquisas sobre a qualidade nutricional da soja e a relação de sua ingestão e os benefícios à saúde, ampliando o nível de informação do consumidor.

Quando questionados sobre a facilidade de adquirir ou não o hábito do consumo de grãos ou derivados de soja, $75 \%$ afirmaram ser fácil adquiri-lo, enquanto que $25 \%$ afirmaram que não.

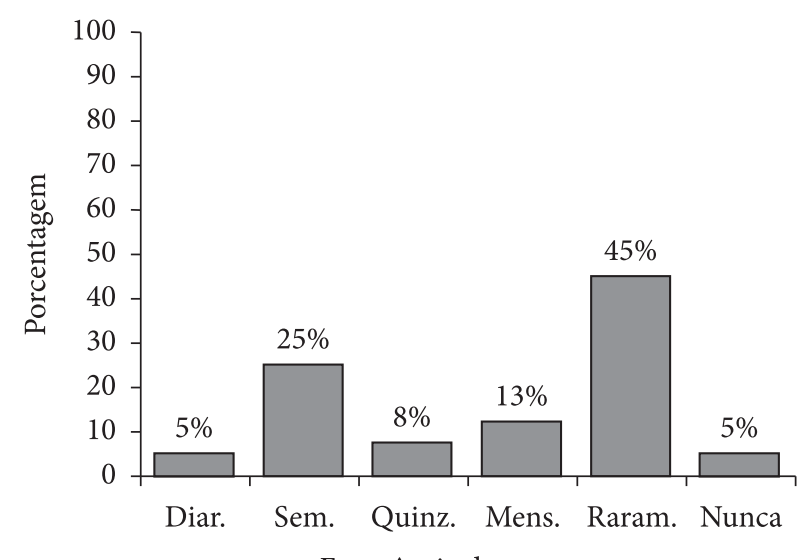

Figura 2. Distribuição dos entrevistados de acordo com a frequência do consumo de soja ou derivados.

Esse resultado é bastante interessante, pois, analisado em conjunto com os resultados anteriores, temos a seguinte situação: $75 \%$ afirmam ser fácil adquirir o hábito do consumo de grãos de soja ou derivados, $95 \%$ consideram que o produto melhora a saúde, no entanto, somente $5 \%$ referem consumi-lo diariamente e $25 \%$ semanalmente (Figura 2). Isso demonstra que apenas o conhecimento quanto aos benefícios à saúde não é suficiente para promover aumento no consumo, mesmo que se considere fácil adquirir esse hábito, pois muitos são os fatores que influenciam a mudança de hábito.

Segundo Hendricks e Badruddin (1992), a seleção de um alimento é influenciada por vários fatores, sendo eles: culturais, sensoriais, econômicos, ambientais, genéticos e familiares. Para Schiffman e Kanuk (2000), a atitude é uma predisposição aprendida pelo indivíduo, formada a partir de suas experiências e informações obtidas, as quais o influenciam a agir favorável ou desfavoravelmente em relação a um determinado "objeto", sendo que este "objeto" pode ser um produto ou categoria de produtos, marcas, serviços, bens, pessoas, conceitos/ideias, propaganda, preço, canais de comércio, mídia, entre outros.

Com base nos valores apresentados em relação às características da população e o comportamento, realizou-se o cruzamento com o intuito de verificar as possíveis correlações. Todos os cruzamentos realizados são apresentados da Tabela 1 a Tabela 6. Assim, foram cruzados os dados da frequência de consumo dos grãos de soja com a facilidade de adquirir o hábito e melhoria para a saúde (Tabelas 1 e 2, respectivamente). Foram realizados os cruzamentos da idade com as variáveis melhoria para a saúde e facilidade de adquirir o hábito (Tabelas 3 e 4, respectivamente) e, por fim, a melhoria para a saúde com as variáveis facilidade de adquirir o hábito e gênero (Tabelas 5 e 6 , respectivamente).

A partir dos cruzamentos realizados, não se observou nenhuma significância estatística entre as variáveis. Isso demonstra que os provadores não correlacionam a melhora da saúde com a frequência de consumo dos grãos de soja (Tabela 1), ou seja, apesar de $95 \%$ dos provadores terem respondido que o consumo deste tipo de produto melhora a saúde, não fazem 
Tabela 1. Descrição tabular do cruzamento da frequência de consumo dos grãos de soja com variável melhoria para a saúde e respectiva significância estatística da relação de dependência entre elas pelo teste Qui-quadrado.

\begin{tabular}{lccrl}
\hline \multicolumn{1}{c}{ Classificação } & Sim & Não & Total & \multicolumn{1}{c}{$\mathrm{P}\left(\chi^{2}\right)$} \\
\hline Diariamente & $2(2)^{*}$ & $0(1)$ & 2 & Obs. $=$ N.S. \\
Semanalmente & $10(8)$ & $0(3)$ & 10 & Tab5\% $\% 11,07$ \\
Quinzenalmente & $2(2)$ & $1(1)$ & 3 & Tab1\% $\% 15,09$ \\
Mensalmente & $5(4)$ & $0(1)$ & 5 & \\
Raramente & $17(14)$ & $1(5)$ & 18 & \\
Nunca & $2(2)$ & $0(1)$ & 2 & \\
Total global & 38 & 2 & 40 & \\
\hline
\end{tabular}

${ }^{\star}$ Os valores esperados se apresentam entre parênteses.

Tabela 2. Descrição tabular do cruzamento da frequência de consumo dos grãos de soja com a variável facilidade de adquirir o hábito e respectiva significância estatística da relação de dependência entre elas pelo teste Qui-quadrado.

\begin{tabular}{lccrl}
\hline \multicolumn{1}{c}{ Classificação } & Sim & Não & Total & $\mathrm{P}\left(\chi^{2}\right)$ \\
\hline Diariamente & $2(2)^{*}$ & $0(1)$ & 2 & Obs. = N.S. \\
Semanalmente & $8(8)$ & $2(3)$ & 10 & Tab5\% $=11,07$ \\
Quinzenalmente & $2(2)$ & $1(1)$ & 3 & Tab1\% $=15,09$ \\
Mensalmente & $5(4)$ & $0(1)$ & 5 & \\
Raramente & $12(14)$ & $6(5)$ & 18 & \\
Nunca & $1(2)$ & $1(1)$ & 2 & \\
Total global & 30 & 10 & 40 & \\
\hline
\end{tabular}

* Os valores esperados se apresentam entre parênteses.

uso dele. $\mathrm{O}$ mesmo acontece entre a frequência e a facilidade de adquirir o hábito (Tabela 2), visto que $75 \%$ acreditam que possam adquirir este hábito com facilidade e a frequência de consumo é baixa.

Não houve interferência nem da idade, facilidade de adquirir o hábito ou gênero sobre a melhoria para a saúde (Tabelas 3, 5 e 6, respectivamente). O comportamento dos indivíduos entrevistados frente à melhoria para a saúde foi independente do sexo ou idade. Não ocorreu correlação entre a idade e a facilidade de adquirir o hábito (Tabela 4).

Os dados obtidos para os atributos dos grãos medidos na análise sensorial são apresentados na Tabela 7 e Figura 3.

Verificou-se que, para o atributo aparência, somente as amostras ST15 e T60 apresentaram diferença significativa $(p \leq 0,05)$ entre si, não diferindo das demais. A ST15 representa a que obteve a maior aceitação, situando-se no atributo "gostei ligeiramente", enquanto que a T60 a menor, encontrando-se na escala "desgostei ligeiramente".

Verifica-se que a umidade teve um papel importante neste resultado, pois a ST15, que recebeu pré-secagem, teve maior aceitação com coloração desejada pelos provadores, enquanto que o tempo de tostagem de 60 minutos (T60) promoveu escurecimento excessivo comprometendo a aparência dos grãos. Segundo Moser (1980) e Van Soest (1994), as condições de umidade e temperatura acima de $55^{\circ} \mathrm{C}$ são favoráveis à ocorrência de reações não enzimáticas entre os carboidratos
Tabela 3. Descrição tabular do cruzamento da idade com a variável melhoria para a saúde e a significância estatística da relação de dependência entre elas pelo teste Qui-quadrado.

\begin{tabular}{lcccl}
\hline \multicolumn{1}{c}{ Classificação } & Sim & Não & Total & \multicolumn{1}{c}{$\mathrm{P}\left(\chi^{2}\right)$} \\
\hline de 18 a 21 anos & $14(13)^{*}$ & $0(1)$ & 14 & Obs. $=$ n.s. \\
de 22 a 25 anos & $10(10)$ & $1(1)$ & 11 & Tab5\% $=7,81$ \\
de 26 a 29 anos & $6(7)$ & $1(0)$ & 7 & Tab1\% $=11,34$ \\
mais de 30 anos & $8(8)$ & $0(0)$ & 8 & \\
Total global & 38 & 2 & 40 & \\
* Os valores esperados se apresentam entre parênteses. & &
\end{tabular}

* Os valores esperados se apresentam entre parênteses.

Tabela 4. Descrição tabular do cruzamento da idade com a variável facilidade de adquirir o hábito e respectiva significância estatística da relação de dependência entre elas pelo teste Qui-quadrado.

\begin{tabular}{lccrl}
\hline \multicolumn{1}{c}{ Classificação } & Sim & Não & Total & \multicolumn{1}{c}{$\mathrm{P}\left(\chi^{2}\right)$} \\
\hline de 18 a 21 anos & $12(11)^{*}$ & $2(4)$ & 14 & Obs. $=$ n.s. \\
de 22 a 25 anos & $7(8)$ & $4(3)$ & 11 & Tab5\% $=7,81$ \\
de 26 a 29 anos & $5(5)$ & $2(2)$ & 7 & Tab1\% $=11,34$ \\
mais de 30 anos & $6(6)$ & $2(2)$ & 8 & \\
Total global & 30 & 10 & 40 & \\
\hline
\end{tabular}

${ }^{*}$ Os valores esperados se apresentam entre parênteses.

Tabela 5. Descrição tabular do cruzamento da melhoria para a saúde com a variável facilidade de adquirir o hábito e respectiva significância estatística da relação de dependência entre elas pelo teste Qui-quadrado.

\begin{tabular}{lclcl}
\hline Classificação & Sim & Não & Total & \multicolumn{1}{c}{$\mathrm{P}\left(\chi^{2}\right)$} \\
\hline Sim & $29(29)^{*}$ & $9(10)$ & 38 & Obs. $=$ n.s. \\
Não & $1(2)$ & $1(1)$ & 2 & Tab5\% $=3,84$ \\
Total global & 30 & 10 & 40 & Tab1\% $\% 6,63$ \\
\hline
\end{tabular}

${ }^{*}$ Os valores esperados se apresentam entre parênteses.

Tabela 6. Descrição tabular do cruzamento da melhoria para a saúde com a variável gênero (sexo) e respectiva significância estatística da relação de dependência entre elas pelo teste Qui-quadrado.

\begin{tabular}{lccrl}
\hline Classificação & Masculino & Feminino & Total & \multicolumn{1}{c}{$\mathrm{P}\left(\chi^{2}\right)$} \\
\hline Sim & $16(16)^{*}$ & $22(22)$ & 38 & Obs. $=$ n.s. \\
Não & $1(1)$ & $1(1)$ & 2 & Tab5\% $=3,84$ \\
Total global & 17 & 23 & 40 & Tab1\% $\% 6,63$ \\
\hline
\end{tabular}

${ }^{*}$ Os valores esperados se apresentam entre parênteses.

solúveis e grupos aminas dos aminoácidos, resultando na reação de Maillard, que resulta em alteração na coloração dos grãos.

De acordo com Davis (1995), a reação de Maillard é considerada como a mais importante no processo de escurecimento dos alimentos tratados pelo calor, podendo influenciar tanto positiva quanto negativamente na qualidade do alimento submetido ao tratamento térmico.

No caso da soja, esta influência é considerada positiva, pois se assemelha ao que acontece na torrefação do café e do cacau, em que a reação de Maillard é responsável pelo desenvolvimento da coloração e dos aromas agradáveis que os caracterizam (HOSKIN, 1994).

Esse resultado demonstra que houve, devido à tostagem, melhora na aparência do produto, principalmente na amostra 
Tabela 7. Média das notas conferidas aos atributos avaliados nos grãos de soja tostados por diferentes tempos.

\begin{tabular}{|c|c|c|}
\hline Atributos & Tratamentos $^{3}$ & Médias \\
\hline \multirow[t]{6}{*}{ Aparência } & ST10 & $5,55 \pm 2,09^{1 \mathrm{ab} 2}$ \\
\hline & ST15 & $5,85 \pm 1,73^{\mathrm{a}}$ \\
\hline & $\mathrm{T} 45$ & $4,85 \pm 1,92^{\mathrm{ab}}$ \\
\hline & $\mathrm{T} 50$ & $5,18 \pm 2,30^{\mathrm{ab}}$ \\
\hline & T60 & $4,43 \pm 2,22^{\mathrm{b}}$ \\
\hline & Controle & $5,60 \pm 2,72^{\mathrm{ab}}$ \\
\hline \multirow[t]{6}{*}{ Aroma } & ST10 & $4,90 \pm 1,55^{\mathrm{b}}$ \\
\hline & ST15 & $6,05 \pm 1,38^{\mathrm{a}}$ \\
\hline & $\mathrm{T} 45$ & $4,98 \pm 1,33^{\mathrm{b}}$ \\
\hline & T50 & $5,68 \pm 1,91^{\mathrm{ab}}$ \\
\hline & T60 & $5,45 \pm 1,78^{\mathrm{ab}}$ \\
\hline & Controle & $4,83 \pm 1,41^{\mathrm{b}}$ \\
\hline \multirow[t]{6}{*}{ Sabor } & ST10 & $4,65 \pm 2,26^{b}$ \\
\hline & ST15 & $5,88 \pm 1,92^{\mathrm{a}}$ \\
\hline & $\mathrm{T} 45$ & $4,68 \pm 2,08^{\mathrm{b}}$ \\
\hline & T50 & $6,28 \pm 2,21^{\mathrm{a}}$ \\
\hline & T60 & $5,55 \pm 2,34^{\mathrm{ab}}$ \\
\hline & Controle & $2,85 \pm 1,63^{c}$ \\
\hline \multirow[t]{6}{*}{ Textura } & ST10 & $3,60 \pm 2,18^{c}$ \\
\hline & ST15 & $4,95 \pm 2,05^{\mathrm{b}}$ \\
\hline & $\mathrm{T} 45$ & $3,93 \pm 2,10^{\mathrm{bc}}$ \\
\hline & $\mathrm{T} 50$ & $6,95 \pm 1,93^{\mathrm{a}}$ \\
\hline & T60 & $6,48 \pm 1,91^{\mathrm{a}}$ \\
\hline & Controle & $3,35 \pm 2,29^{c}$ \\
\hline
\end{tabular}

${ }^{1}$ Média \pm desvio padrão. ${ }^{2}$ Médias seguidas de letras iguais, nas colunas, não diferem entre si pelo teste de Tukey, ao nível de significância de $5 \%(\mathrm{p} \leq 0,05) .{ }^{3}$ Tratamentos: T1 - com pré-secagem +10 minutos de forno; $\mathrm{T} 2$ - com pré-secagem +15 minutos de forno; T3 - sem pré-secagem +45 minutos de forno; T4 - sem pré-secagem +50 minutos de forno; $\mathrm{T} 5$ - sem pré-secagem +60 minutos de forno.

que recebeu pré-secagem e ficou mais tempo exposta ao calor, mas, mesmo assim, não foi efetivamente apreciada pelos provadores a ponto de obter médias equivalentes a gostei muito ou extremamente.

Em relação ao atributo aroma (Tabela 7), observa-se que novamente a amostra ST15 obteve a maior aceitação, diferindo estatisticamente $(p \leq 0,05)$ da ST10, T45 e controle. Semelhante ao que aconteceu com a aparência, neste atributo, a ST15 também se situa no termo hedônico "gostei ligeiramente". A ST10 e a T45 foram as que receberam os menores tempos de tostagem nos diferentes tratamentos aplicados, enquanto que o controle foi exposto somente à temperatura de estufa $\left(55^{\circ} \mathrm{C}\right)$, diferindo da ST15 que foi exposta ao maior tempo de tostagem após pré-secagem. Esse resultado também pode ser explicado pela ocorrência da reação de Maillard em decorrência da tostagem, visto que, como consequência desta reação, são produzidos cores e aromas agradáveis quando os alimentos são corretamente processados (NUNES; BAPTISTA 2001).

Pela análise dos resultados em relação ao sabor (Tabela 7), observou-se que todas as amostras diferiram significativamente $(\mathrm{p} \leq 0,05)$ do controle. As amostras ST15, T50 e T60 obtiveram a maior aceitação, situando-se no termo hedônico "gostei ligeiramente", e também diferiram estatisticamente $(\mathrm{p} \leq 0,05)$ das amostras ST10 e T45. O T60 somente diferiu do controle.

A aceitação da soja e seus produtos sofrem restrições devidas, principalmente, ao seu sabor considerado desagradável. Esse sabor característico denominado beany flavor, ou sabor de feijão cru, é originado da associação de compostos carbonílicos de cadeia curta com a fração proteica, sendo catalisados pelas enzimas lipoxigenases (MONTEIRO et al., 2004). Entretanto, sabe-se que o emprego do tratamento térmico inativa essas enzimas. Pode ocorrer melhora desse sabor com o emprego de branqueamento dos grãos, porém esse processo não foi realizado no presente estudo.

Em estudo realizado por Brown et al. (1982), os autores verificaram que, em temperaturas superiores a $91{ }^{\circ} \mathrm{C}, 99 \%$ das lipoxigenases podem ser inativadas. $\mathrm{O}$ controle não recebeu tratamento térmico em temperatura superior a $55^{\circ} \mathrm{C}$, temperatura não suficiente para interromper o processo de catalisação dos ácidos graxos, resultando em produto com sabor inferior às demais amostras que foram tostadas.

Todavia, quanto ao tratamento com pré-secagem, o maior tempo de exposição ao calor (ST15) foi o mais eficiente para produzir um produto mais agradável ao paladar. Dos tratamentos sem pré-secagem, o tempo intermediário (T50) mostrou-se mais eficiente.

Apesar das alterações benéficas promovidas pela tostagem, ainda assim não houve boa aceitação por parte dos provadores, mostrando que o consumo do produto é realmente influenciado por vários fatores e não apenas por aspectos nutricionais.

Quanto ao atributo textura (Tabela 7), as amostras T50 e T60 situaram-se nos termos hedônicos "gostei moderadamente" e "gostei ligeiramente", respectivamente, obtendo maior aceitação, diferindo significativamente $(\mathrm{p}<0,05)$ das amostras ST10, ST15, T45 e controle. Com relação a estas últimas, somente a ST15 diferiu significativamente $(\mathrm{p}<0,05)$ da ST10 e controle. Isso demonstra que os tratamentos sem pré-secagem, com os maiores tempos de exposição ao calor, ou seja, 50 e 60 minutos, foram os mais eficazes quanto à textura, fazendo com que o produto se tornasse mais crocante e, assim, mais apreciado em relação à textura.

Fazendo-se uso do teste de Qui-quadrado (Figura 3), é possível verificar a frequência com que cada amostra foi escolhida pelos provadores em comparação aos valores que eram esperados. Em todos os atributos, a frequência observada foi significativa $(\mathrm{p} \leq 0,01)$.

No atributo aparência, o controle foi o que mais agradou aos provadores, obtendo a maior frequência nas escalas 8 e 9 , estando a frequência observada bem acima da esperada. Em seguida, vem o tratamento ST15 nas escalas 6 e 7. O T45 foi o que ficou na média das preferências, visto que foi a maior frequência na escala 5. O T60 foi o mais rejeitado, pois obteve a maior frequência nas escalas 2 e 3 . Essa análise é importante para perceber qual a frequência de distribuição, o que não pode ser visualizado através do teste de Tukey (Tabela 7), pois no referido teste não é possível verificar que, da escala 6 a 9, as duas amostras mais preferidas quanto à aparência se referem 


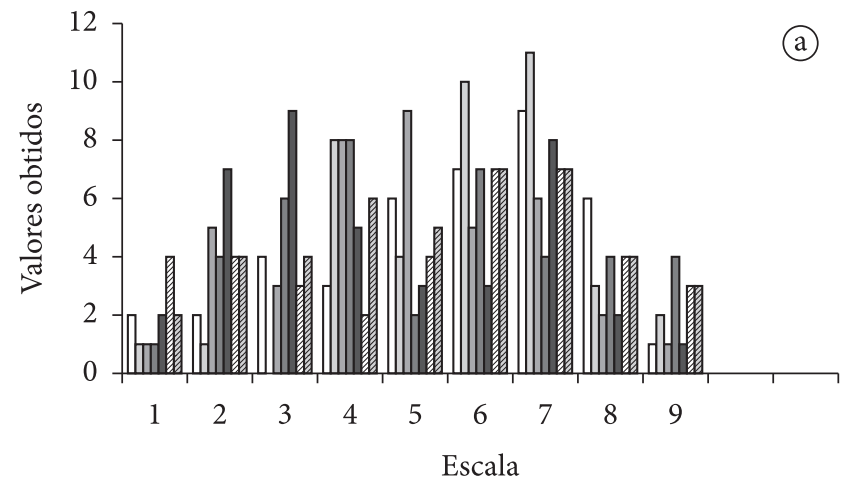

Obs. $=65,75^{\star *}$

Tab 5\% $=55,76$

Tab $1 \%=63,69$

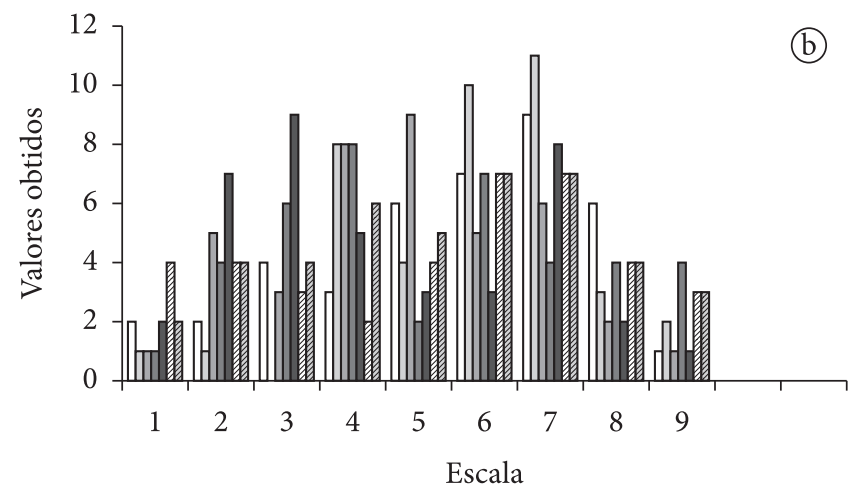

Obs. $=98,59^{* *}$

Tab $5 \%=55,76$

Tab $1 \%=63,69$

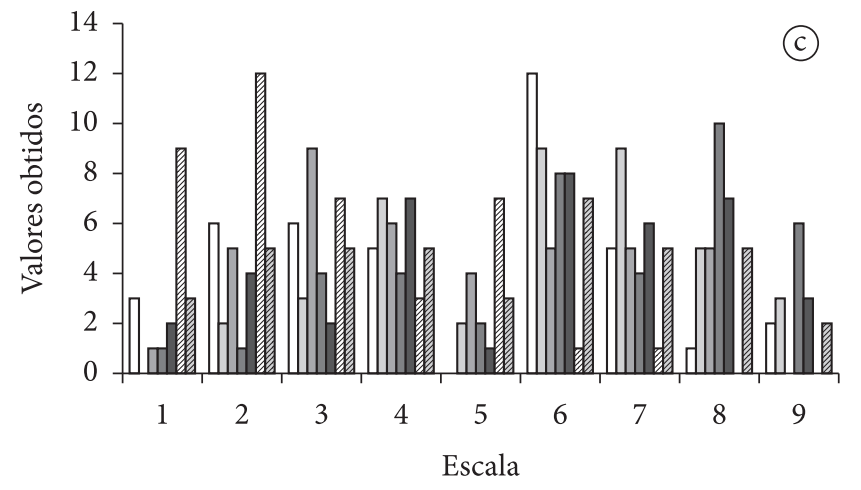

Obs. $=84,69^{* *}$

Tab $5 \%=55,76$

Tab $1 \%=63,69$

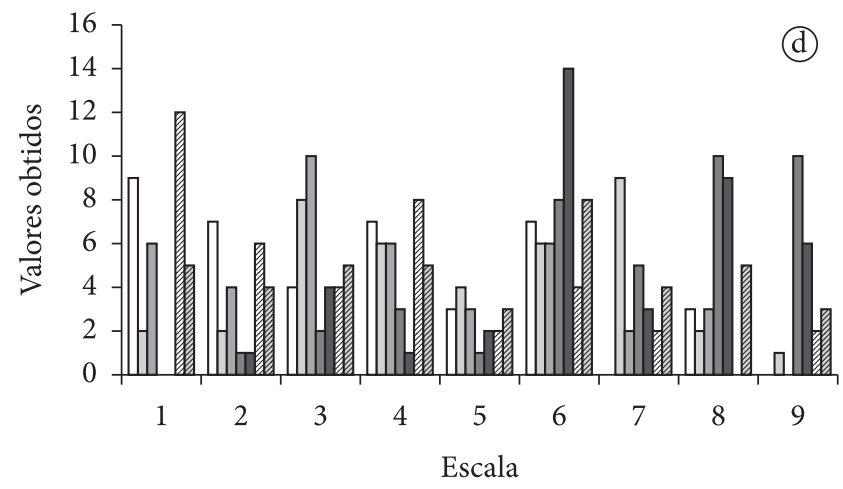

Obs. $=118,6^{* *}$

Tab $5 \%=55,76$

Tab $1 \%=63,69$

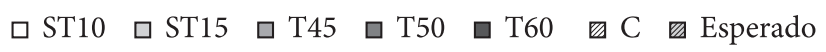

Figura 3. Distribuição das variáveis: a) aparência; b) aroma; c) sabor; d) textura; segundo a escala hedônica (CHAVES; SPROESSER, 1996) e respectiva significância estatística da relação de dependência entre elas pelo teste de Qui-quadrado. ${ }^{*}$ Valor significante ao nível de $1 \%$ pelo teste de Qui-quadrado. Tratamentos: ST10 - com pré-secagem + 10 minutos de forno; ST15 - com pré-secagem + 15 minutos de forno; T45 - sem pré-secagem + 45 minutos de forno; T50 - sem pré-secagem + 50 minutos de forno; T60 - sem pré-secagem + 60 minutos de forno; C - Controle e Esperado - Valor esperado.

ao ST15 e controle. No teste de Tukey, o ST15 obteve a maior média, confirmando a boa aceitação, mas o mesmo não acontece com o controle quando se analisa a média.

Quanto ao aroma, o T50 obteve a maior frequência tanto na escala 8 como na 6. Nesta última, o T60 vem logo em seguida, ficando os tratamentos T50 e T60 bem próximos quanto à preferência. Já o ST15 obteve valor bastante expressivo na escala 7. O controle ficou na média, sendo o preferido na escala 5. Os demais foram os mais rejeitados, sendo o T45 maior na escala 4 e o ST10 na escala 3. Comparando o resultado encontrado ao teste de Tukey (Tabela 7), confirma-se que o ST15 apresentou a maior aceitação, sendo o T50 e T60 os posteriores. No entanto, nota-se que o controle obteve a menor aceitação (Tabela 7), o que não é confirmado no teste de Qui-quadrado, pois este se destacou na escala 5 e não abaixo desta, representando maior rejeição.
No quesito sabor, o T50 foi o preferido (escalas 8 e 9), seguido do ST15 na escala 7 e do ST10 na escala 6. O controle e o T45 foram os mais rejeitados, pois aparecem com maior frequência nas escalas inferiores a 5 . Em relação ao teste de Tukey (Tabela 7), este confirma o resultado, exceto quanto ao ST10 e T45, que não apresentaram diferença significativa entre si ( $p>0,05)$, porém, observando as distribuições referentes às frequências, verifica-se que foram bem distintas.

Na escala 9, o T50 foi o preferido quanto à textura. Já na escala 8 , o T50 e o T60 tiveram frequências bem próximas, mostrando que ambas foram bem aceitas pelos provadores. O ST15 obteve a maior frequência na escala 7. Em ordem decrescente de escala, o controle, T45 e ST10 foram os menos apreciados. Esse resultado foi confirmado pelo teste de Tukey (Tabela 7), visto que neste caso as médias estão similares à distribuição observada. 


\section{Conclusões}

De acordo com o teste de análise sensorial empregado, o tratamento que promoveu a maior aceitabilidade dos grãos de soja tostados foi o que recebeu o tempo intermediário de 50 minutos, entre os que não foram submetidos à pré-secagem. Sugere-se que o tratamento térmico proporciona melhora da palatabilidade devido à inativação das lipoxigenases contidas nos grãos de soja. Pode ser observada também a necessidade de maior incentivo para o consumo, já que há o conhecimento da importância da soja, porém o conhecimento não corresponde à ação, independente de idade e sexo.

\section{Agradecimentos}

À FAPESP pelo auxílio financeiro para a realização da pesquisa. À estagiária Viviane Aparecida Petruz e à Prof. ${ }^{a}$ Dr. ${ }^{a}$ Maria Isalina Ferreira Alves (in memoriam) pela realização das análises estatísticas.

\section{Referências bibliográficas}

ANDERSEN, P. K. Survival analysis 1982-1991: The second decade of the proportional harzards regression model. Statistics in Medicine, v. 10, n. 12, p. 1931-1944, 1991.

AXELROD, B.; CHEESBROUGH, T. M.; LAAKSO, S. Lipoxygenases in soybean. Methods Enzymology, v. 71, p. 441-451, 1981.

BEHRENS, J. H.; SILVA, M. A. A. P. Atitude do consumidor em relação à soja e produtos derivados. Ciência e Tecnologia de Alimentos, v. 24, n. 3, p. 431-439, 2004.

BRASIL. Ministério da Saúde. Normas para pesquisa envolvendo seres humanos (Resolução CNS n 196/96 e outras). 2. ed. ampliada. Brasília: Ministério da Saúde, 2003. 64 p.

BROWN, B. D. et al. Minimizing protein insolubilization during thermal inactivation of lipoxygenase in soybean cotyledons. Journal of the American Oil Chemist's Society, v. 59, n. 2, p. 88-92, 1982.

BURT, C. The factorial analysis of qualitative data. British Journal of Psychology, v. 3, p. 166-185, 1950.

CANTO, W. L.; TURATTI, J. M. Produção e mercado de produtos intermediários de soja no Brasil. Boletim do Centro de Pesquisa e Processamento de Alimentos, v. 2, n. 7, p. 111-139, 1989.

CHAVES, J. B. P.; SPROESSER, R. L. Práticas de laboratório de análise sensorial de alimentos e bebidas. Viçosa: Imprensa Universitária, Universidade Federal de Viçosa, 1996. 81 p.

CHIARELLO, M. D. A soja e os alimentos funcionais: oportunidades de parcerias em $\mathrm{P} \& \mathrm{D}$ para os setores público e privado. Revista Parcerias Estratégicas, n. 15, p. 48-60, 2002.

CHUNG, T. K. H. et al. A randomized, double-blind, placebocontrolled, crossover study on the effect of oral estradiol on acute menopausal symptoms. Maturitas, v. 25, n. 2, p. 115-123, 1996.

CLARK, J. W. et al. Effects of tyrosine kinase inhibitors on the proliferation of human breast cancer cell lines and proteins important in the RAS signaling pathway. International Journal of Cancer, v. 65, n. 2, p. 186-191, 1996.

CLEMENTI, S. et al. Food quality optimization. Food Quality and Preference, v. 2, p. 1-12, 1990.

COMPANHIA NACIONAL DE ABASTECIMENTO - CONAB. Safra de grãos. Disponível em: <http://www.conab.gov.br/conabweb/ download/safra/4levsafra.pdf>. Acesso em: 08 jul. 2007.
DALlA-CORTE, A.; MODA-CIRNO, V.; SCHOLZ, M. B. S. Enviroment effet on grain quality in early common bean cultivars and lines. Crop Breeding and Applied Biotechnology, v. 3, n. 3, p. 193-202, 2003.

DAVIS, E. Functionality of sugars: physicochemical interactions in foods. American Journal of Clinical Nutrition, v. 62, Suppl., p. 170S-177S, 1995.

EMPRESA BRASILEIRA DE PESQUISA AGROPECUÁRIA EMBRAPA. Reunião anual de pesquisa de soja da região Sul 2000. 2000. Disponível em: <www.cnpt.embrapa.br/i_soja.htm>. Acesso em: 14 jul. 2003.

GALLAGHER, J. C. et al. The effect of soy protein on bone metabolism. Journal of Nutrition, v. 130, n. 3, p. 667s, 2000.

GREENACRE, M. J. Correspondence analysis in practice. London: Academic, 1993. $193 \mathrm{p}$.

HENDRICKS, K. M.; BADRUDDIN, S. Weaning recommendations: the scientific basis. Nutrition Reviews, v. 50, n. 50, p. 125-133, 1992.

HOSKIN, J. C. Sensory properties of chocolate and their development. American Journal of Clinical Nutrition, v. 60, Suppl., p. 1068S-1070S, 1994.

KING, J. M. et al. Processing of lipoxygenase free soybeans and evaluation in foods. Journal of the American Oil chemists' Society, v. 78, n. 4, p. 353-360, 2001.

MEILGAARD, M.; CIVILLE, G. V.; CARR, B. T. Sensory evaluation techniques. $2^{\text {nd }}$ ed. Boca Raton: CRC Press, 1991. 354 p.

MONTEIRO, M. R. P. et al. Qualidade protéica de linhagens de soja com ausência do inibidor de tripsina Kunitz e das isoenzimas lipoxigenases. Revista de Nutrição, v. 17, n. 2, p. 195-205, 2004.

MOSER, L. E. Quality of forages as affected by post-harvest storage and processing. In: FAHEY JUNIOR, G. C. (Ed.). Crop quality storage, and utilization. Madison, Wisconsin: American Soybean Association, 1980. p. 227-260.

MOSKOWISTZ, H. R. Applied sensory analysis of foods. Boca Raton: CRC Press, 1988. 259 p.

MOZZONI, L. A.; MORAWICKI, R. O.; CHEN, P. Canning of vegetable soybean: procedures and quality evaluations. International Journal of Food Science and Technology, v. 44, n. 6, p. 1125-1130, 2009.

NUNES, C. S.; BAPTISTA, A. O. Implicações da reacção de Maillard nos alimentos e nos sistemas biológicos. Revista Portuguesa de Ciências Veterinárias, v. 96, n. 536, p. 53-59, 2001.

OLIVEIRA, A. F.; CARVALHO, G. R. Evolução das elasticidades-renda dos dispêndios de leite e derivados no Brasil. In: CONGRESSO DA SOCIEDADE BRASILEIRA DE ECONOMIA E SOCIOLOGIA RURAL, 45., 2006, Fortaleza. Anais... Disponível em: <www.sober. org.br/palestras/5/1025.pdf>. Acesso em: 09 out. 2009.

PIMENTEL-GOMES, F. Curso de estatística experimental. 10. ed. São Paulo: Nobel, 1982. 430 p.

RACKIS, J. J.; SESSA, D. J.; HONIG, D. H. Flavor problems of vegetable food proteins. Journal of the American Oil Chemist's Society, v. 56, n. 3, p. 262-271, 1979.

SAVAGE, W. D. et al. Biologically active components inactivation and protein insolubilization during heat processing of soybean. Journal of Food Science, v. 60, n. 1, p. 164-180, 1995.

SCHIFFMAN, L. G.; KANUK, L. L. Comportamento do consumidor. 6. ed. Rio de Janeiro: Livros Técnicos e Científicos, 2000.

SETH, K. K.; NATH, N. A simple blanch-dry process for lipoxygenase inactivation in soybeans cotyledons. International Journal of Food Science and technology, v. 23, n. 3, p. 275-279, 1988. 
SHEU, S. C.; CHEN, A. O. Lipoxygenase as blanching index for frozen vegetable soybeans. Journal of Food Science, v. 56, n. 2, p. 448-451, 1991.

SILVA, J. B. et al. Aceitabilidade de bebidas preparadas a partir de diferentes extratos hidrossolúveis de soja. Pesquisa Agropecuária Brasileira, v. 42, n. 12, p. 1779-1784, 2007.

STATISTICAL ANALYSIS SYSTEM INSTITUTE - SAS. SAS/QC software: usage and reference (version 6). 2. ed. Cary, 1996. 1 CD-ROM.

STONE, H.; SIDEL, J. L. Sensory evaluation practices. $3^{\text {rd }}$.ed. London: Academic Press, 2004. 408 p.

TORRES-PENARANDA, A. V. et al. Sensory characteristics of soymilk and tofu made from lipoxygenase-free and normal soybeans. Journal of Food Science, v. 63, n. 6, p. 1084-1087, 1998.
TORRES-PENARANDA, A.V.; REITMEIER, C. A. Sensory descriptive analysisof soymilk. Journal of Food Science, v. 66, n. 2, p. 352-356, 2001.

VAN SOEST, P. J. Nutritional ecology of the ruminant. 2. ed. Ithaca: Comstock Publishing, 1994. 476 p.

VASCONCELOS, I. M. et al. Nutritional study of two Brazilian soybean (Glycine max) cultivars differing in the contents of antinutritional and toxic proteins. Journal of Nutrition and Biochemistry, v. 12, n. 1, p. $55-62,2001$.

VEN, C. V. D.; MATSER, A. M.; BERG, R. W. V. D. Inactivation of soybean trypsin inhibitors and lipoxygenase by soybean trypsin inhibitors and lipoxygenase by high-pressure processing. Journal of Agricultural and Food Chemistry, v. 53, n. 4, p. 1087-1092, 2005. 